\title{
De estereotipos, violencia y sexismo: la construcción de las mujeres en los medios mexicanos y argentinos ${ }^{*}$
}

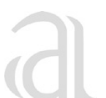 \\ Mg. Paola Bonavitta \\ Lic. Jimena de Garay Hernández
}

Recibido: 25 de enero de 2011

Aprobado: 3 de abril de 2011

\begin{abstract}
Resumen
Los medios masivos de comunicación se constituyen como una poderosa forma de producción y reproducción de la cultura, ya que transmiten discursos e ideologías a gran parte de la población, a través de las representaciones sociales que insistentemente presentan. Algunas de esas representaciones son las relacionadas con el género, las relaciones de poder y la violencia hacia las mujeres. En este artículo se revisan los discursos manejados por medios audiovisuales, periodísticos y digitales en Argentina y en México, discutiendo la influencia que tienen estos en la formación de ideologías y prácticas que denigran a las mujeres y propician la violencia de género.
\end{abstract}

Palabras clave: género, violencia, medios de comunicación, representaciones sociales, mujeres.

Este artículo de investigación científica y tecnológica pertenece a la investigación De estereotipos, violencia y sexismo: la construcción de las mujeres en los medios mexicanos y argentinos, financiada con recursos propios.

Pertenece a CONICET- Centro de Investigaciones Jurídicas y Sociales de la Facultad de Derecho y Ciencias Sociales de la Universidad Nacional de Córdoba. Correo electrónico: paola.bonavitta@gmail.com.

".* Pertenece a la Universidad Nacional Autónoma de México y es estudiante del Programa de Posgrado en Psicología Social de la Universidad do Estado do Rio de Janeiro. Correo electrónico: jime_degaray@hotmail.com 


\title{
About stereotypes, violence, and sexism: woman construction on Mexican and Argentinean communication media
}

\begin{abstract}
Mass communication media are becoming a powerful means of culture production and reproduction since they transmit discourses and ideologies to most part of population through the social representations they insistently present. Some of those representations are the ones related to gender, power relations, and violence with women. This article reviews discourses managed by audiovisual, journalistic, and digital communication media in Argentina and Mexico, by discussing the influence of these media on the creation of ideologies and practices which denigrate women and promote violence against women.
\end{abstract}

Key words: Gender, violence, communication media, social representation, women.

\section{Resumo}

A mídia de massa se constitui como uma poderosa forma de produção e reprodução da cultura, já que transmite discursos e ideologias a uma grande parte da população através das representações sociais que apresenta repetidamente. Algumas dessas representações estão relacionadas ao gênero, às relações de poder e à violência contra as mulheres. Neste artigo se revisam os discursos manipulados pela mídia audiovisual, jornalística e digital na Argentina e no México, discutindo a influência que esses discursos têm na formação de ideologias e práticas que denigrem as mulheres e propiciem a violência de gênero.

Palavras-chave: gênero, violência, mídia de massa, representações sociais, mulheres 


\section{Introducción}

Los medios masivos de comunicación (en adelante $\mathrm{MMC}$ ) son formadores de ideología. Si bien cuentan con una función informativa-educativa, los cambios sociales generados a partir de la segunda mitad del siglo XX -en relación con los nuevos ritmos de trabajo, con las nuevas y diversas familias, etcétera- han hecho de los MMC uno de los grandes formadores de personalidades, de deseos, intereses y aspiraciones. Es por esto que se los ha catalogado de "cuarto poder", pues la influencia que ejercen en la formación socio-cultural de las personas es sumamente intensa. Los MMC construyen realidades, visiones del mundo, representaciones sociales sobre determinadas temáticas.

Siguiendo a Champagne (2000), los medios fabrican colectivamente una representación social a partir de su discurso -el cual circula masivamente- y por ello es capaz de movilizar tanto prejuicios como manifestaciones sociales masivas. Así, el autor remarca que, lo que se denomina "acontecimiento", no es más que la movilización -que puede ser espontánea o provocada- de los medios alrededor de algo que, durante un cierto tiempo, conviene en considerar como tal. Dicho autor argumenta que "los medios son parte integrante de la realidad o producen efectos de realidad al fabricar una visión mediática de aquella que contribuye a crear la realidad que pretende describir. En particular, las desdichas y reivindicaciones deben expresarse mediáticamente si quieren tener una existencia públicamente reconocida" (Champagne, 2000).

En este artículo, se apuntó a descifrar los mensajes violentos hacia las mujeres que se expresan, de manera implícita y explícita, en los MMC. Desde una mirada interdisciplinaria, que abarca los estudios de comunicación, los estudios culturales latinoamericanos y la psicología social, se buscó comprender e interpretar las representaciones sociales que crean los medios de comunicación sobre las mujeres y cómo estas representaciones reproducen el androcentrismo y el patriarcalismo dominante y se convierten, así, en reproductoras y hacedoras de la violencia contra las mujeres.
Los estudios sobre recepción de MMC han tenido siempre en cuenta especialmente a las mujeres, por ser consideradas un público sumamente activo, entre otras cosas, por ser las que pasan más horas frente a la televisión, por ser quienes permanecen más tiempo en el ámbito doméstico y por ser, además, las consumidoras número uno de telenovelas. Como se dijo anteriormente, los MMC son formadores de opiniones, deseos, creencias y representaciones. Pero éstas responden a los intereses del patriarcado dominante. Se estereotipa a las mujeres bajo los prototipos construidos por el androcentrismo, que constituye la adopción que la sociedad ha construido históricamente de un punto de vista central, que pretende homogeneizar a todas las personas bajo los mismos parámetros hegemónicos (Alfarache, 2003). Dicho punto de vista es un sesgo, un prejuicio centrado en las prácticas, cuerpos, intereses y espacios de los varones (Serret, 2008).

Un elemento fundamental por el cual los estereotipos de mujeres que transmiten los MMC obedecen a los intereses del patriarcado es el acceso muy limitado de las mujeres a los medios de comunicación y las tecnologías de información, en términos de representación y de empleo (Vega Montiel, 2010). Las imágenes estereotipadas que sobre ellas prevalecen en estas industrias, así como su escasa participación como propietarias y productoras, han sido señaladas como poderosas barreras que dificultan la universalidad de los derechos humanos.

Estas imágenes estereotipadas sobre las mujeres refuerzan la violencia de género contra las mujeres y las niñas, considerada, siguiendo a Marcela Lagarde (2006), como la conducta que incluye cualquier agresión física, psicológica, sexual, patrimonial, económica o feminicida dirigida contra mujeres y niñas por el hecho de ser tales. Es un tipo de violencia que se produce en un esquema de poderes desiguales, que busca someter y controlar a las mujeres y las niñas, que las daña y lesiona y que transgrede sus derechos humanos (Vega Montiel, 2010). La violencia contra las mujeres y niñas es el mecanismo utilizado por los hombres para asegurar el mantenimiento 
del poder y el disfrute de privilegios. En este sentido, la violencia ha sido articulada en nuestras estructuras e ideologías, y es admitida por una serie de convenciones sociales, leyes e instituciones (ibíd.). De esta manera, la violencia contra mujeres y niñas constituye la vía para reestablecer el poder masculino y que los hombres utilizan para afirmar su virilidad. Es un mecanismo compensatorio individual para cada hombre, al mismo tiempo que constituye el mecanismo socialmente aceptado para afirmar el control y el poder masculino (ibíd.).

La violencia contra mujeres y niñas incluye: violencia física, psicológica, sexual y económica. Así, la violencia contra mujeres y niñas tiene diversas manifestaciones, se vale de distintos medios y produce distintas consecuencias; no se limita al maltrato físico o psicológico, pues trasciende a todas las esferas de la vida (Vega Montiel, 2010). Además, constituye un problema estructural que afecta su habilidad para participar en proyectos de desarrollo, para ejercer su ciudadanía y para realizar sus derechos en democracia (Carrillo, 1992; Lori, 1994). La violencia que sufren las mujeres es estructural, pues se refuerza y retroalimenta en los asimétricos entretejidos sociales, en los hogares, en las relaciones interpersonales, en el mercado de trabajo, en las instituciones jurídicas, en la vida en las comunidades y en todos los niveles y grupos sociales (Maquieira, 2006). Al mismo tiempo, es "una forma de hacer negocios", pues reporta enormes beneficios económicos a los hombres (Kaufman, 2009). Junto con el control del poder, la percepción que los hombres tienen de su derecho a privilegios -insultar o golpear a su cónyuge, al percibir que es de su propiedad, o acosar e incluso violar a una mujer, al percibir que tiene el privilegio del placer-, están en la base de la violencia: "tal sentimiento sólo exacerba las inseguridades masculinas: si la masculinidad es una cuestión de poder y control, no ser poderoso significa no ser hombre. De nuevo, la violencia se convierte en el medio para probar lo contrario ante sí mismo y ante otros" (ibíd.). Por ello, la urgencia de desmantelar las estructuras de poder y privilegios de los hombres y erradicar el permiso cultural que se les admite para violentar la vida y dignidad de las mujeres y las niñas.

Por otra parte, la unidad de análisis del trabajo empírico que hemos realizado está constituida por la representación, puesto que es una categoría que nos permite comprender los procesos de construcción social de sentido y ubicar el proceso mediante el cual los medios de comunicación producen significados. Las representaciones sociales constituyen un proceso de reconstrucción de lo real, de relaciones entre sujetos y sociedad, gracias a las cuales las personas hacen inteligible la realidad (Moscovici, 1976). Son conjuntos de conceptos e imágenes originados en la cotidianidad y en la comunicación y tienen dos funciones primordiales: proporcionar a las personas un medio de otorgar sentido a su mundo y facilitar la posibilidad de compartir ideas (Collier, et al., 1991). Sin embargo, esta facilitación no provee precisamente de un medio social justo e igualitario, ya que permite que se generen significados poco cuestionados en los que algunas personas no cuentan con los mismos derechos que otras.

Además, las representaciones sociales tienen necesariamente implicaciones éticas, pues expresan y definen las normas del grupo, indicando lo que es aceptable y lo que no lo es, lo que se debe hacer y lo que no, lo que es normal y lo que no lo es (Rouquette, 2005). A partir de dichas representaciones, concebimos no sólo al mundo, sino a nosotros mismos, ya que éstas son "construcciones simbólicas individuales y/o colectivas a las que los sujetos apelan para interpretar el mundo, reflexionar sobre su propia situación y la de los demás y determinar el alcance y la posibilidad de su acción histórica" (Vasilachis, 2003, p. 268). Moscovici planteó que las representaciones sociales mantienen las modalidades de relación dentro y entre los grupos. Así, las creencias grupales (que forman parte de las representaciones sociales) instan al proceso de diferenciación o pertenencia, que es central en la constitución de la identidad social. Igualmente, la comunicación por medio de la cual se transmiten, construyen e intercambian dichas representaciones sociales se constituye por significaciones correspondientes a la vida social, de 
forma que sostiene identidades, ya que proviene de ellas (Contreras y Silva, 2006).

En cuanto a las representaciones sociales de género, estas cumplen una función fundamental: la de la reproducción del sistema patriarcal, mediante la socialización y educación de los discursos que circulan en la prensa. Y esta representación es la que se encuentra en la base de la violencia contra las mujeres, pues naturaliza el castigo y la venganza dañina como derechos legítimos ejercidos sobre las mujeres, y es por ello que los vemos como naturales (Vega Montiel: 2010). Los medios de comunicación construyen creencias y opiniones que se estructuran como reglas sociales (Vega Montiel: 2010). En su discurso se transmite la mirada patriarcal y opresora de género de manera naturalizada, y se producen y reproducen los fenómenos de discriminación y exclusión (Maquieira, 2006).

La representación social, como categoría de análisis, nos permite corroborar en esta investigación que distintos tipos de violencia y discriminación contra las mujeres y las niñas son reproducidos por los MMC. Si bien reproducen distintos tipos de violencia y discriminación contra las mujeres y las niñas, los MMC no consideran que esto fuere un problema, sino que no es otra cosa que parte de la conducta socialmente admitida, por lo cual las enunciaciones que los programas de televisión hacen no van dirigidas a un conocimiento ni toma de conciencia social acerca de este problema, sino a su reproducción. El objetivo que el contenido del discurso mediático expresa tiende a trivializar el problema, mas no a identificarlo y mucho menos a denunciarlo.

Por otra parte, los planteamientos teóricometodológicos en que se sustenta el presente trabajo se circunscriben al ámbito del análisis del discurso entendido éste, globalmente, como el estudio de la relación entre el lenguaje y los contextos en que se usa (Mc Carthy, 1991). Como el discurso representa la principal materialización de la ideología en sentido amplio, supone una manera de actuar sobre un auditorio con fines prácticos, que funciona como creador y sostén de maneras de pensar, hablar y actuar: o sea, formas de vida y visiones de mundo. Está dirigido a toda la ciudadanía con el propósito de persuadir acerca de las visiones de mundo.

Para definir la noción de "discurso", se parte de Michel Foucault, quien encuentra que el discurso supone en realidad una noción material. Para este autor, el mismo discurso es ya información, no es un mero transmisor sino que su producción está complejamente regulada de acuerdo con ciertos intereses. El objeto del discurso no es el simple mensaje que el autor quiso lanzar, sino que todo el proceso discursivo (incluyendo figuras tan "naturales" como la del propio "autor") está lleno de implicaciones y de formalizaciones concretas de las relaciones saber-poder, que responden a determinados intereses concretos que tratan de "ocultarse" tras esa aparente "ingenuidad", "inocencia" de todo "discurso" en tanto que realidad material (Foucault, 1992, p. 20).

En este trabajo, el centro serán las representaciones sociales que construyen y transmiten los MMC en Argentina y México. ¿Y qué es lo que traducen las representaciones sociales?: el sistema ideológico existente.

Partiendo de los estudios de género, se considera que el género constituye una representación toral del sistema social, en tanto lugar en el que se cruzan discursos, creencias y normas sobre lo que la identidad femenina y masculina representa y sobre la relación de poder que priva entre ambos géneros, y que se ha traducido históricamente en la supremacía masculina sobre la subordinación femenina. Esos discursos, estereotipos y creencias se visibilizan en la desigualdad de género que se expresa en la dimensión social, pero también en la económica, la jurídica, la política y la cultural, lo que origina el trato discriminatorio de las mujeres (Flores-Palacios, 1996). Por tanto, la perspectiva de género se formula como "un punto de vista a partir del cual se visualizan los distintos fenómenos de la realidad (científica, académica, social o política), que tiene en cuenta las implicaciones y efectos de las relaciones sociales de poder entre los géneros" (Serret, 2008, p. 15).

En este punto, se reconoce que la representación social del género es creada y reproduci- 
da por las instituciones sociales clave: la familia, la escuela, los gobiernos, los partidos políticos y los medios de comunicación, a través de distintas y variadas tecnologías sociales (de Lauretis, 1987). Y es por ello que esta investigación se ha situado en el ámbito de las representaciones sociales, pues ofrecen la posibilidad de preguntarnos y respondernos, como lo afirma Márgara Millán (1996) "sobre el lenguaje y sus formas, lo que construyen y dejan fuera", y también, acerca de la actuación de los medios de comunicación en relación con la organización homogeneizadora y dicotomizante de las relaciones de género.

En este sentido, se reconoce que los MMC son pieza clave en la producción de tales representaciones, pues, como Pedraza (2008) plantea,

... realizan una nominación y organización de lo real (considerada además legítima e institucional) que se arraiga en los modos en que los individuos interpretan y actúan en la sociedad, se estabilizan y refuerzan las relaciones de poder [...] Esto lleva implícita una dominación discursiva de las perspectivas ideológicas que tienen mayor peso en la estructura social: el orden burgués, el orden patriarcal [...] (p. 41).

De esta forma, la importancia de los MMC en el ámbito de las representaciones sociales, se halla en su poder de construir creencias y opiniones que se estructuran como reglas sociales. Desde luego, los medios realizan dichas representaciones apegados a las normas y principios de construcción de la realidad del grupo social, sin embargo, tienen el poder de influir en la conciencia social, y por lo tanto, de transformar la propia realidad.

Los MMC han sido señalados como una institución con una responsabilidad central en la erradicación de la violencia contra las mujeres y, en consecuencia, en la realización de sus derechos humanos. Al constituirse como una fuente de educación -formal e informal- para la sociedad, al lado de la familia y de la escuela, tienen una tarea central en la búsqueda de soluciones.

Es en este marco que los organismos internacionales emitieron recomendaciones a los MMC, en aras de que examinen las consecuencias de la reproducción de estereotipos sexistas en su programación, incluidos aquellos contenidos en los anuncios publicitarios que promueven la violencia y la discriminación de género; y de que adopten medidas para eliminar esas imágenes negativas, con miras a promover una sociedad basada en los principios de equidad y respeto, esenciales para el desarrollo y la paz de las naciones (Vega Montiel, 2010).

Así también, de generar una conciencia acerca de la responsabilidad que tienen las instituciones mediáticas en la promoción de imágenes no estereotipadas de mujeres y hombres y de eliminar los modelos de conducta generadores de violencia que en ellos se presentan, así como de alentar a las personas responsables de producir los contenidos a que establezcan directrices y códigos de conducta profesionales. Y por último, de sensibilizar sobre su importante función en lo relativo a informar y educar a la población acerca de las causas y los efectos de la violencia contra las mujeres y a estimular el debate público sobre el tema (Vega Montiel, 2010).

Las recomendaciones más importantes realizadas por dos instancias fundamentales en este debate -la Plataforma de Acción de Beijing y la Convención Belem Do Pará-, señalan que las industrias audiovisuales tienen el deber de 1. Adoptar todas las medidas necesarias para eliminar los prejuicios y las prácticas consuetudinarias y de otro tipo basadas en la idea de inferioridad o la superioridad de uno u otro sexo y de los estereotipos asignados a mujeres y hombres. 2. Elaborar directrices adecuadas de difusión que contribuyan a erradicar este problema.

Por su parte, el objetivo número 18 de los Objetivos de Desarrollo del Milenio (ODM) señala: En colaboración con el sector privado, hacer accesibles los beneficios que ofrecen las nuevas tecnologías, especialmente las de informática y comunicación.

Así también, varios encuentros regionales han tratado la relación entre MMC y género, y han dado como resultado los siguientes puntos:

- Quito, 1994: 1. La comunicación de género como tema y práctica se reconoce como estratégica para el avance de las mujeres. 2. Garantizar a las mujeres las libertades de información y 
de expresión. 3. Elaborar diagnósticos sobre los estereotipos sexistas en los medios de comunicación. 4. Crear el Foro permanente de Comunicación de Género.

- Toronto, 1995: 1. Incrementar la participación de las mujeres en la propiedad, la producción y la decisión sobre contenidos. 2. Garantizar el acceso de las mujeres a la libertad de expresión y de información. 3. Impulsar a los Estados a emitir recomendaciones: a. A empresarios de medios, para que adopten programas de acción positivos que promuevan la participación igualitaria de las mujeres en la industria. b. A asociaciones profesionales de medios de comunicación, para que incrementen la participación de comunicadoras profesionales (periodistas, productoras, etc.). c. A instituciones educativas, para que impulsen estrategias de recepción para las audiencias femeninas. d. A gobiernos, para que realicen las reformas estructurales en materia de medios de comunicación que garanticen el acceso de las mujeres a los derechos comunicativos. e. A organizaciones de la sociedad civil, para que lleven a cabo diagnósticos sobre la representación de las mujeres en los medios de comunicación.

Por otra parte, un espacio fundamental para la discusión y el acuerdo sobre acciones positivas en torno a la comunicación y el género fue la Cuarta Conferencia Mundial de la Mujer que tuvo lugar en Beijing, en 1995. Esta Conferencia recogió e hizo propia la preocupación de las comunidades científicas y organizaciones sociales por la forma en la cual los medios representan a las mujeres, y por su acceso desigual a la propiedad y la producción de los medios de comunicación; de ahí que por primera vez la Plataforma de Acción señalara la necesidad de incrementar la participación de las mujeres en la propiedad, la producción y la decisión sobre los contenidos, al tiempo que ofreciera una mirada y diseñara estrategias para impulsar el acceso y participación de las mujeres en los medios tradicionales y en las nuevas tecnologías de la información y la comunicación.

La Plataforma de Beijing señala que al abordar el problema de la movilización de los medios de difusión, los gobiernos y otros sectores deberían fomentar una política activa y visible de incorporación de una perspectiva de género en sus políticas y programas mediante un Objetivo Estratégico: aumentar el acceso de la mujer y su participación en la expresión de sus ideas y la adopción de decisiones en los medios de difusión y por conducto de ellos, con las nuevas tecnologías de comunicación, de tal forma que la Plataforma plantea adoptar las siguientes medidas: 1. Fomentar la educación, la capacitación y el empleo de las mujeres e igual acceso a todas las esferas y niveles de los medios de difusión; 2. Fomentar desde la perspectiva de género la imagen de las mujeres en los medios de difusión; 3. Promover la participación plena y equitativa en los medios de difusión; 4. Procurar se distribuyan equitativamente los nombramientos de mujeres y hombres en los órganos consultivos, de gestión, de reglamentación o de supervisión, incluidos los relacionados con los medios de difusión privados y estatales o públicos; 5 . Alentar a esos órganos, en la medida en que ello no atente contra la libertad de expresión, a que aumenten programas destinados a las mujeres y realizados por mujeres para velar porque los problemas de las mujeres sean tratados apropiadamente; estimular y reconocer las redes de comunicación de mujeres y apoyar su participación en todos los ámbitos de los medios de difusión y sistemas de comunicación; 6. Alentar la utilización creativa de programas con miras a divulgar información sobre las formas culturales de la población indígena; 7. Garantizar la libertad de los medios de difusión y su protección dentro del marco del derecho nacional y alentar la participación positiva de los medios en las cuestiones sociales y de desarrollo.

Por tanto, si el derecho a la comunicación indica que Toda persona tiene derecho a expresarse, a ser escuchada, a ser reconocida, a ser proyectada con dignidad, a recibir información con base en la transparencia, la diversidad, la participación y la justicia social y económica, quienes desarrollamos nuestra investigación en esta línea, creemos que la comunicación es un derecho humano esencial, extendible, para la ciudadanía plena de las mujeres.

Por último, es importante recalcar que los MMC pueden constituirse como transformadores 
sociales, dado que gracias a ellos la información sobre los acontecimientos mundiales puede difundirse rápidamente, y colaborar en la eliminación de las fronteras materiales y simbólicas, y por tanto generar una conciencia de interconectividad entre las diferentes luchas sociales que conduzca a una idea de una organización social desinstitucionalizada (Maquieira, 2006).

\section{Metodología}

En este trabajo se utilizó el Análisis del Discurso, que consiste en establecer el contenido semántico de los conceptos correspondiente a los términos efectivamente utilizados en determinados textos, cuyo análisis se considera interesante para determinada finalidad. La razón de ser de las gramáticas del texto era poder proveer una descripción explicita de las estructuras (gramaticales) de los textos. La tarea más obvia de tal descripción era dar cuenta de las relaciones (semánticas) de coherencia semántica entre oraciones (Van Dijk, 1972).

El Análisis de Discurso le da prioridad a la interacción social, que es la unidad básica de dicha disciplina. El lenguaje es un proceso social, por lo que este método se centra en tres aspectos: función -forma en que las personas (o en este caso los MMC) utilizan el lenguaje para hacer cosas-, variación -el lenguaje depende del propósito de la conversación- y la construcción -las personas usan el lenguaje para construir versiones de la realidad social- (Collier, et.al., 1991). Este enfoque metodológico se constituye como una heurística presentada como alternativa a las investigaciones sociales, al centrarse en el lenguaje y, particularmente, en las prácticas discursivas de los agentes sociales (Ibáñez, 1994).

Para comprender cómo los medios construyen representaciones sociales en torno a las mujeres, es importante considerar no sólo qué escriben, dicen o muestran, sino también cómo lo hacen, en otras palabras, no sólo el contenido sino también la enunciación. Se examinaron los mensajes mediáticos en México y Argentina (telenovelas, publicidades, canciones) que, en términos de contenido, dicen todos aproximadamente lo mismo, pero que, sin embargo, lo dicen de muy diferentes maneras (Verón, 2001). Así, se ve lo implícito de los discursos, lo que está en la oscuridad en los mismos, para poder interpretar los estereotipos y representaciones que formulan sobre las mujeres y cómo estos contribuyen a fortalecer la violencia de género.

Debido a que se trabajó con variedad de productos emitidos por los MMC, se dividieron estos productos en revistas para la mujer, telenovelas juveniles, publicidades, diarios y medios digitales:

\section{- Revistas para la mujer}

Se analizaron revistas dedicadas a la mujer (Revista Tú, Cosmopolitan, Para Ti). En ellas se construye un estereotipo de mujer interesada en conquistar al sexo opuesto, dispuesta a hacer todo lo posible para ser considerada atractiva, deseada, interesante e imprescindible frente a la mirada masculina.

Bajo titulares como "Poderes para ser perfecta" (Tú), o "Cómo ser irresistible para un hombre" (Cosmopolitan), las mujeres reciben una serie de tips o consejos que les permitirán volverse el centro de atención de los hombres, ser como ellos esperan que ellas sean. Entre los "secretos" que se divulgan para que la mujer atraiga al sexo opuesto están: "Deja que tu boyfriend pase tiempo con sus amigos, vaya a jugar futbol, de camping o a un concierto", "Sonríe siempre y elimina, si es que la tienes, esa cara de que algo huele mal todo el tiempo" o "Si te portas posesiva, gritona, loca y maníaca con las amigas o compañeras de escuela de tu nene, te dejará". De esta manera, la mujer debe comportarse de determinada manera, sonreír todo el tiempo, mostrarse feliz. No se hace hincapié en ningún momento en que ella debe realizar las actividades que le gustan (sino sólo que debe permitirle a él que las realice), o pasar tiempo con sus amigas. Se muestra a la mujer como una persona que vive por y para su pareja, una persona que tiene que respetar las necesidades del otro y no las suyas. Lo mismo sucede con su humor: la consigna es "pase lo que pase, sonríe". Además, estas revistas señalan cómo debe vestirse y producirse una mujer: "Unos labios carnosos pintados de rojo y un es- 
cote de infarto harán que cualquier chico cruce la habitación para ir por ti" (Cosmopolitan). De esta manera, se prevé que la única manera de "conquistar" a un hombre es mostrar partes del cuerpo femenino, consideradas como sexualmente activas (los pechos) y, además, contar con unos labios carnosos (¿qué sucede con quien no los tiene?). Este tipo de noticias no sólo violenta a la mujer al imponer que se debe tener en cuenta lo que el hombre espera de ella sino que también determina cómo debe verse la mujer para atraer; esto trae aparejadas otras violencias: reducción del autoestima (frente a la imposición de ideales inalcanzables), la no aceptación del sí-misma, la exigencia de ser aquello que no se es, entre otras.

Asimismo, estas revistas debaten acerca de si es adecuado o no tener sexo en la primera noche, basándose en cuestiones éticas y morales (impuestas, además, por el patriarcado); enseñan "trucos" para darle más placer en las relaciones sexuales al hombre (no se hace referencia a que sea la mujer quien obtenga ese placer, sino que sea la dadora) y muestran los "bikinis ultra-hots" para ser sumamente atractiva en la playa, pero debemos tener en cuenta que son bikinis diseñados para un cuerpo perfecto, donde es la mujer quien debe perfeccionarse para caber y lucirse en esos bikinis y no que el bikini se adapte a los cuerpos reales.

El estereotipo de mujer que construyen estas revistas es el de una mujer que está constantemente pensando en cómo atraer, cómo dar placer, cómo conquistar y cómo hacer que su pareja (quien, además, se da por sentado que es una pareja heterosexual) no se aburra de ella y permanezca a su lado. No es una mujer proactiva, independiente, con deseos personales propios. A pesar de ser una mujer preocupada por su imagen, por su físico, por su rostro, se continúa reforzando el ideal de la mujer reproductora e inserta en el plano doméstico, que espera a su pareja impecablemente vestida y producida, al mejor estilo estrella de Hollywood, y satisface todos sus deseos para que él sea un hombre feliz y satisfecho en los planos sexual y emocional. La mujer debe esforzarse para todo: para gustar, para verse bien, para cumplir con los deseos de él, para tener una cierta talla, para cumplir con los ideales de belleza establecidos socio-culturalmente. Y todas las opciones son válidas para cumplir con los objetivos planteados: cirugías, masajes, dietas, gimnasio, etcétera. Así, podemos observar un cierto engaño por parte de la sociedad y de los MMC: la supuesta "liberación sexual", en la que se acepta que las mujeres cuiden de su cuerpo y experimenten su sexualidad simplemente encubre el mismo estereotipo que se les ha adjudicado a lo largo de la historia, que es el "ser para otros". La abnegación y entrega siguen siendo las características más valoradas en las mujeres, sean éstas amas de casa con sobrepeso o atractivas ejecutivas. Al final, prevalece el objetivo de ser "una dama en la mesa y una tigresa en la cama".

\section{- Telenovelas juveniles}

Las telenovelas adolescentes dan cuenta de los ideales de belleza instaurados por la sociedad patriarcal y misógina. En ellas se encuentran protagonistas antagónicas: la linda (que es, a su vez, malvada) y la fea (pura y buena). Se hace referencia directa a su imagen física: su rostro, su cuerpo, su manera de vestir. El grado de popularidad que alcanzan estas mujeres va directamente relacionado con su belleza. También es frecuente que se incluyan los estereotipos de clase social, siendo la "linda y malvada" rica y la "fea y buena" pobre, papeles que también juegan importantes roles en las interacciones de los personajes. Especificando, se puede ver en una telenovela como "Patito Feo" (cuya versión original es argentina y luego se realizó en México) que se presentan dos bandos: las divinas y las populares. Las divinas están compuestas por chicas bonitas, populares, deseadas por los chicos, exitosas, que bailan y cantan bien. Las populares, por su parte, se componen de niñas catalogadas, por las demás y por sí mismas, como "feas".

La canción principal de la telenovela (que incluye musicales) repite: "Todos saben quién manda en esta school, porque nosotras somos gente cool (...) Sea como sea, aquí no entran feas (...) Eres horriblemente fea, aquí no puedes entrar". La separación es explícita: por un lado las 
divinas, las chicas lindas, y por el otro las feas, que no tienen ningún tipo de acercamiento a aquellas que cumplen con ideales de belleza. El mensaje, para las y los televidentes, remarca que "si eres buena pero fea no tienes ningún tipo de éxito con los chicos". Además, este es un claro ejemplo de que los MMC son reproductores y productores de representaciones sociales, pues el hecho de que las divinas canten esta canción insultando a las populares reproduce la violencia que se lleva a cabo en muchas escuelas y ámbitos de la vida de las adolescentes (llamada bullying) y continúa instaurando la idea de que las personas que cumplen con los estándares de belleza tienen el derecho y prácticamente la necesidad de discriminar y agredir a las que no los cumplen (especialmente a las mujeres), mientras que las demás deben plegarse a dicha violencia. Esta canción y los comportamientos observados en la telenovela refuerzan esas representaciones sociales de género y dan nuevas ideas para que las jóvenes actúen en las escuelas siguiendo dichos modelos.

En el caso de Betty, la fea (realizada en México bajo el nombre de Lety, la fea), la historia es similar. La protagonista es inteligente, capaz, responsable, buena, amable y simpática. Pero no cumple con ninguno de los requisitos de belleza preestablecidos. La protagonista, tras generar diversos cambios en su imagen, en su físico y en su manera de vestir, logra ser aceptada por su entorno y enamora, finalmente, al protagonista. Pero, a pesar de que alcanza sus metas (tanto personales como profesionales), previamente debe verse bella (según su contexto social) para lograr deslumbrar al protagonista de la historia. También se puede observar que, al cambiar su apariencia, siente que debe modificar otros elementos de acción cotidiana, tales como su forma de hablar y de caminar. Es decir, el carácter dulce con el que interactuaba normalmente, "debe" alterarse para completar la representación social de una mujer deseable y atractiva sexualmente. Así se constituye la imagen compartida socialmente de lo que debe ser una mujer "bella", no sólo en la forma de verse por parte de Lety, sino en el proceso de interiorización de su nuevo aspecto, y en los significados que las televidentes perciben al ver dicha telenovela.

Si nos remontamos unos años atrás, la telenovela Carrusel de Niños (realizada en México y transmitida en toda Latinoamérica) también presentaba un conflicto similar: la niña rubia, hermosa y rica (María Joaquina) enamoraba a sus compañeritos. Las cualidades eran similares a las que pueden verse en Patito Feo: linda y malvada. Las demás niñas eran buenas, adorables, queridas por sus compañeros, pero no lograban atraer ni enamorar al resto de los infantes. Igualmente, estas otras niñas (especialmente Laura, quien tenía un problema de sobrepeso) eran foco de burlas y otros tipos de violencia, lo cual se consideraba "normal", pues al no cumplir con los requisitos de belleza, eran "merecedoras" de discriminación. En esa telenovela en particular, se observa también una discriminación por raza, pues Cirilo, un niño afrodescendiente, es severamente discriminado por parte de María Joaquina. Es así como se ve el entrecruzamiento de las representaciones sociales correspondientes a género, raza, etnia, clase social, las cuales son utilizadas para establecer jerarquías entre las personas y para justificar la violencia hacia los grupos no hegemónicos.

En Rebelde Way (RBD, para la versión mexicana), sucede lo mismo: la protagonista es bella, atractiva, deseada, con un cuerpo perfecto, pero con actitudes déspotas, autoritarias y discriminadoras hacia el resto del grupo. Discrimina a uno de sus compañeros por ser un migrante, al resto de sus compañeras por feas, por gordas o por pertenecer a un estrato social más bajo. Los chicos la desean a pesar de sus constantes negativas y maltratos.

Los mensajes que se transmiten a niñas y adolescentes en estas telenovelas son siempre los mismos: para tener éxito con el sexo opuesto debes ser bella, tener un cuerpo perfecto y, además, ser despectiva con los demás niños y niñas, pues, parece, que en las novelas no se mezclan valores humanitarios con belleza (todas las lindas son malas y todas las feas son buenas).

En las nuevas telenovelas juveniles, el amor ya no se vive con un llanto constante, el drama a 
flor de piel, el abandono del hombre sobre la mujer, como en las novelas de antaño. Ahora, el llanto se transformó en trato despectivo, inhumano, en palabras hirientes, en prototipos de belleza que aseguran el éxito. Esto les exige a las jóvenes cumplir con esos ideales para pertenecer, para ser parte de... En la adolescencia, donde el sentirse parte de un grupo se vuelve fundamental, los MMC educan sobre el "cómo insertarse" y, ante todo, sobre "el cómo verse para poder insertarse".

\section{- Publicidades}

Un caso paradigmático son las publicidades de productos de limpieza, las cuales tienen un destinatario exclusivo: las mujeres. El enunciatario que construyen las publicidades es una mujer que necesita de un hombre constantemente: para limpiar eficazmente, para poder llevar el carrito del supermercado, para conseguir productos de las góndolas o estantes, etc. La mujer construida por las publicidades es completamente dependiente del hombre, delgada, bella, trabaja en el hogar pero siempre está hermosa para recibir a su pareja con la casa impecable. Físicamente, roza la perfección, pero es dependiente e incapaz de resolver los quehaceres domésticos por sí misma (en un ámbito tradicional y androcéntricamente asignado a las mujeres, basado en la dicotomía cartesiana de privado/público, femenino/masculino).

Las publicidades de bebidas alcohólicas (cervezas, fernet, tequila), van dirigidas exclusivamente a los hombres. La mujer aparece como un objeto. En algunos casos ni siquiera se muestra su rostro, sino su cuerpo (ideal, con amplio escote y corta falda o pollera). Se las estereotipa como fáciles de conquistar si se les acerca una bebida alcohólica y como poco inteligentes para discernir entre lo que un hombre aparenta y lo que es. Aquí se refuerza el papel dominante del hombre (conquistador, exitoso, a pesar de no ser atractivo físicamente) y el papel pasivo de la mujer, que cae rendida a los pies del varón poseedor de la bebida. Asimismo, la mujer no consume alcohol, éste es destinado a ellos, lo cual refuerza la representación social de la mujer como reservada.
En este caso es importante recalcar que estos comerciales resaltan en gran parte el "deber ser" del hombre, lo cual contribuye también a la violencia de género, pues se restringen las posibilidades identitarias tanto de hombres como de mujeres, al establecer una única manera de ser. Al exaltar el papel de "macho" que deben de jugar los hombres, se obstaculiza el cuestionamiento que tanto ellos mismos como las mujeres puedan realizar a los estereotipos, lo cual es una causa de violencia sumamente común en la actualidad.

En el caso de los comerciales o anuncios de las toallitas femeninas, se muestra a una mujer que debe ocultar su menstruación. Las toallitas le permiten salir de la casa, sin visibilizar lo que ocurre en su cuerpo. Ello reprime la sexualidad: nadie debe saber lo que está pasando y son las toallitas las encargadas de disimularlo. A pesar de que el tema de la menstruación se ha abierto en los últimos años, pues no se puede olvidar que antes era un tabú y ni siquiera se podía hablar públicamente de ello ni mucho menos anunciar dichos productos, es importante considerar que el tema sigue restringiéndose sólo a las mujeres. Únicamente son ellas las que pueden comprar estos productos, y son las únicas que pueden entender los procesos físicos por los que transitan a lo largo de los ciclos menstruales. El tema se mantiene entre mujeres, y los hombres son completos ignorantes al respecto. Además, es interesante observar un poco más allá, en cuanto a que tanto estos productos como sus anuncios continúan presentando elementos ligados a la representación social de lo femenino: los colores rosa y violeta, las flores, las mariposas, entre otros, los cuales refuerzan dichas representaciones.

Las publicidades de perfumes femeninos muestran a mujeres hermosas, ideales de belleza inalcanzables. Ellas expresan su sensualidad y elegancia, además, están protegidas por un hombre. Ellas ocupan un lugar pasivo en el juego de seducción: sólo utilizan un perfume que las convierte en sensuales e irresistibles. Ellas deben oler bien para recibir la atención de los hombres. Lo mismo ocurre con las publicidades de champú y de cremas: la mujer no los usa para 
ella misma, sino para convertirse en un objeto de deseo. Las publicidades no buscan la satisfacción de la mujer, sino la de los hombres, reforzando la idea mencionada anteriormente: "las mujeres viven para otros". Si en la actualidad, dado que muchas más mujeres que antes reciben remuneración económica, pueden acceder a dichos productos, su función será ser agradables para las demás personas, especialmente para los hombres. Relacionado con esto, no se tiene en cuenta el despertar la seducción en personas del mismo sexo: las relaciones que se plantean son relaciones exclusivamente heterosexuales, donde la mujer es la que lleva el peso mayor, es decir, el "deber de" gustar, de atraer, de ser perfecta.

- Diarios: Noticias sobre violencia doméstica

La violencia doméstica es presentada en los diarios o periódicos en la sección Policiales, Justicia, u otros nombres, pero siempre marcando la condición de delito y no de problemática social, que atañe a todas y todos. Si bien los diarios pretenden ser objetivos, esta condición es imposible y los periodistas realizan recortes de la información que nos permiten visualizar lo implí cito del discurso periodístico.

Los MMC utilizan la lógica causa-consecuencia en sus titulares: "Mató a su mujer porque lo echaron del trabajo"; "Mató y cortó en pedazos a su mujer por negarse a tener sexo"; "Mató por celos a su esposo"; "Joven mató a su padre por una discusión por un grabador". En estos titulares, la violencia tiene un porqué, está justificada. Hay un hecho previo (único, exclusivo e irreductible) que dictamina por qué ocurrió un asesinato, una violación, golpes. No hay crítica alguna hacia el hecho violento, no hay castigo, más aún, se los califica de "crímenes pasionales", justificando, tras las pasiones, un hecho violento y aberrante. Esto reincide en el binarismo cartesiano que forma parte de nuestra ideología: razón contra emoción. Se reproduce la idea de que los sentimientos "impiden" que seamos conscientes de lo que estamos haciendo.

No se profundiza en las violencias anteriores que sufrió la víctima; esas otras violencias quedan invisibilizadas. Sólo importa el hecho puntual, el que dispara el suceso noticioso. Se recurre al amarillismo con tal de atraer la atención de los lectores, se ignoran las voces de profesionales que puedan generar una reflexión, un debate o informar sobre las diferentes violencias contra la mujer.

Asimismo, en los diarios sólo se publican hechos que atañen a la violencia física, y se desconocen los demás tipos de violencia contra la mujer. Importa el cómo del hecho y el porqué (reducido a un hecho previo, disparador de la situación violenta) y no se habla del victimario como un sujeto violento, sino como alguien que tuvo un motivo determinado para actuar de esa manera. La mujer-víctima no aparece como tal, sino como la desencadenante de su propia muerte, la culpable, la provocadora, la que causó celos a su pareja por haberse salido de su rol de "ser para otros". Estos son los estereotipos que se ven perpetuados en los MMC, ya que, a pesar de que se está haciendo público un acto violento junto a una mujer, no se está visibilizando la problemática, sino que se están reproduciendo las ideas de la justificación de la violencia, de la demarcación de los estereotipos, de la "naturalidad" de las discriminaciones en contra de las mujeres y de otros grupos sociales que no se apegan al hegemónico.

\section{- Medios digitales: el Internet}

La explosión de Internet como medio de comunicación y como proveedor de información social de la manera más rápida y más globalizada que jamás se haya imaginado hace que su análisis en este tema sea fundamental. En la red, existen diversas plataformas de interacción social en las que las representaciones sociales de género pueden ya sea reforzarse o cuestionarse. Desafortunadamente, la primera opción ha sido la que ha ocurrido con más frecuencia y fuerza.

La mayoría (si no es que todos) los productos mencionados anteriormente tienen sus páginas web, donde reutilizan las herramientas para generar más consumo, una de las cuales es el fuerte vínculo simbólico que se ha hecho entre las mujeres y su "ser para otros", especialmente para sus hijos, los cuales se consideran su único interés, función y proyecto en la vida. Por ejemplo, 
una página web de una marca de lácteos, tiene un apartado de "Mujer", donde se podría hablar de la importancia de que las mujeres procuren su propia salud, especialmente (en este caso) de cuidar sus niveles de calcio. Sin embargo, en dicho apartado se dan "Tips para tus hijos", o "Recetas" con el fin de propiciar una calidad de vida a la familia, rol atribuido socialmente a la mujer, y generador de violencia y culpa hacia ella en el caso de que no lo cumpla al pie de la letra, es decir, como marca el androcentrismo dominante.

Por otra parte, el anonimato que Internet puede representar ha sido utilizado para innumerables tipos de violencia de género. Por ejemplo, existen páginas web que ofrecen a sus usuarios (generalmente hombres) conseguirles aventuras amorosas sin que sus parejas se enteren. Sin caer en la normativa del matrimonio monogámico, el cual tiene por su parte muchas herramientas para violentar a las mujeres, es de llamar la atención la forma en que dicho servicio se propone. Las imágenes presentadas son generalmente de hombres que son satisfechos sexualmente, y se propician, en gran parte, el engaño y el secreto, los cuales no son precisamente los medios de cuestionar la forma hegemónica de relaciones amorosas más adecuados.

Relacionado también con el anonimato, es importante señalar el peligroso y frecuente fenómeno de acoso sexual a través de la red, en el cual generalmente hombres mayores abusan de su invisibilidad para obtener información, de niñas, niños y adolescentes, a partir de lo cual ocurren innumerables formas de violencia de género, desde el acoso sexual hasta la prostitución infantil.

Por otro lado, es un fenómeno interesante el manejo de la propia imagen a través de las diversas redes sociales. A diferencia de otros MMC, los medios digitales tienen como principal característica el intercambio de información entre usuarias y usuarios, rompiendo los límites de la pasividad mediática. Sin embargo, la presentación del mí mismo o mí misma se puede convertir también en un reforzamiento de los procesos antes mencionados (discriminación, ideales de belleza, violencia). Las personas eligen las foto- grafías y la información de sí mismas que desean sea publicada, con lo cual tienen cierto control sobre la imagen que quieren proyectar, y permiten que prácticamente cualquier persona pueda juzgar, también públicamente, nuestra identidad.

Otro proceso significativo es la plataforma de YouTube, donde no sólo se incluyen videos de personas involucradas en el medio del espectáculo, sino donde cualquier persona puede expresarse por dicho medio de forma audiovisual. A través de este portal, la violencia de género y la discriminación pueden ser reproducidas de una forma sumamente potente.

Por último, es importante recalcar que la Internet también puede resultar una importantísima fuente de información en contra de estos estereotipos. Por ejemplo, a través de la red, las mujeres violentadas se pueden enterar de organizaciones no gubernamentales que las apoyen, o de procedimientos legales para solucionar su situación. Sin embargo, también es fundamental subrayar que muchísimas personas alrededor del mundo, la mayoría de ellas mujeres, no tienen acceso a Internet, ya sea porque viven en comunidades muy alejadas de dicho fenómeno o porque sus sociedades no les permiten acceder a dicho medio. Esto también representa violencia.

\section{Conclusiones}

Como se ha visto, se observa un vínculo entre los elementos de las representaciones sociales de género que nos presentan los medios y la violencia de género: los ideales de belleza en los que tanto insisten propician una discriminación ideológica hacia las personas que no los cumplen, la cual, al llevarse a la práctica, se manifiesta en los diferentes tipos de violencia: violencia hacia los cuerpos de las mujeres, hacia sus mentes y hacia sus sentimientos. Y, lo peor de todo, es que muchas veces dicha violencia es difícil de percibir, pues se sustenta y se justifica. Un ejemplo de esto es la anorexia que sufren no sólo las púberes y adolescentes que se dejan impactar por los poco sanos modelos que presentan los MMC, sino las mismas encarnaciones de dichos modelos así como el incremento de las cirugías plásticas que 
apuntan a cumplir con los ideales de belleza impuestos mediáticamente.

Ciertamente, no es fácil percibir que esto implica violencia de género, pues no hay un agresor claro. El punto es que el agresor es la sociedad entera, que se sostiene en los pilares del sexismo, el clasismo, el racismo y el heterocentrismo. Y esto sucede en todos los casos de violencia. Esto es lo que los MMC deben visibilizar. La mujer se sacrifica, hace sufrir a su cuerpo para agradar a otros, se violenta a sí misma para conseguirlo. Esta violencia se justifica, porque lo importante no es que sea quien decide ser, sino que cumpla con el "deber ser". Ella quiere ser una "Divina", una "María Joaquina", y a quien discrimina, finalmente, es a sí misma. El no cumplir con los estereotipos impuestos por los MMC acarrea frustración, decepción, desconsuelo, disminución de la estima, en fin: violencia sobre mujeres y niñas.

En este trabajo, asimismo, se analizaron productos mediáticos argentinos y mexicanos y, como hemos podido observar durante el análisis, no hay variación en cuanto al contenido del mensaje transmitido por los medios. Si bien existen diferencias socio-culturales entre ambos países, éstas no se visibilizan en los productos analizados. El estereotipo es el mismo: mujer perfecta, siempre predispuesta para satisfacer al hombre, incapaz de realizar tareas por sí misma, abocada a sus hijos y esposo... por ende: la violencia se hace visible en la exigencia de perfección de las mujeres y en la justificación de la violencia que ejercen los hombres sobre ellas. El resultado: una insatisfacción constante por no poder alcanzar esos objetivos planteados desde los medios.

De esta manera, se considera que los MMC no están empleando su gran capacidad de visibilización, difusión y generación de conciencia acerca de problemas sociales que parten de la rigidez de las representaciones sociales que se manejan en la actualidad, sino que están siendo cómplices y actores importantes en la perpetuación de dicha estrechez de pensamiento. A pesar de considerarse un "cuarto poder", no están propiciando una sociedad más democrática y tolerante, sino que están generando nuevas formas de violencia, más sutiles, más modernas. Es necesario impulsar una mirada crítica hacia los estímulos gráficos, audiovisuales y digitales, de forma que sea posible plantear un gran abanico de posibilidades de ser mujer y de ser hombre.

¿Qué es lo que está sucediendo? Sólo estamos rebobinando la cinta una y otra vez. Son actores y actrices diferentes, productos diferentes, concepciones diferentes, pero continúan el control y la jerarquización social. Continúan, al fin, las mismas garras: el patriarcado, el androcentrismo, el sexismo, el capitalismo, el etnocentrismo, entre otras.

Los MMC, con su función de formar, informar y educar, deben propender a acabar con los postulados sexistas, racistas y discriminadores impuestos por el androcentrismo. Contribuir a forjar una mirada crítica sobre la sociedad actual, eliminar las diferencias genéricas y la violencia sobre mujeres y niñas, colaborar con la equidad de género son desafíos y obligaciones de los MMC para lograr una sociedad más justa y más equitativa.

\section{Referencias bibliográficas}

Alfarache, Á. (2003). Identidades lésbicas y cultura feminista: una investigación antropológica. México: UNAM, $\mathrm{CEIICH}$.

Champagne, P. (2000). La visión mediática. En Bourdieu, Pierre (Ed.) La miseria del mundo. Buenos Aires: Fondo de Cultura Económica.

Collier, G., et.al. (1991). Escenarios y tendencias de la psicología social. México: Tecnos

Contreras, R. y Silva, M. (2006). La representación social de dos ciudades: México y Querétaro. En (Arciga, Salvador) Miradas psicosociales a la realidad psicosocial (p 397-418). México: Universidad Autónoma Metropolitana.

Ibáñez, T. (1994). Psicología social construccionista. México: Universidad de Guadalajara

Foucault, M. (1992) El orden del discurso. Buenos Aires: Tusquets Editores.

(1992) Genealogía del poder. Tercera edición. Buenos Aires: Ediciones La Piqueta. 
García, G. (2007). Psicología social y género. En (Aguilar y Reid) Tratado de Psicología Social. Perspectivas socioculturales (96-119). México: Anthropos

Lagarde, M. (2006). Por la vida y la libertad de las mujeres, fin al feminicidio. En Russell, D. y Harmes, R. (Eds) Feminicidio: una perspectiva global. México: Universidad Nacional Autónoma de México.

Maquieira, V. (2006). Mujeres, globalización y derechos humanos. Madrid: Ediciones Cátedra.

Rouquette, M. (2005 julio-diciembre). Sobre una categoría específica de representaciones sociales en psicología política. En Psicología Social. Revista internacional de psicología social. Vol. 1 (No. 4). p. 159-164

Serret, E. (2008). Quées y para qué es la perspectiva de género. Oaxaca: Instituto de la Mujer Oaxaqueña.

UNIFEM (2005) Camino a la igualdad de género. CEDAW, Beijing y los ODM. México: UNIFEM

Vasilachis, I. (2003) Pobres, pobreza, identidad y representaciones sociales. Barcelona: Gedisa Editorial.

Van Dijk, T. (2001). El análisis crítico del discurso y el pensamiento social. Atenea Digital No 1, pp. 18-24.
(1992) Text and Context: Explorations in the Semantics and Pragmatics of Discourse. Londres: Longman.

(1980) Macrostructures: an interdisciplinary study of global structures in discourse, interaction, and cognition, Hillsdale, N.J.: L. Erlbaum Associates.

(1972) Some aspects of text grammars. A study in theoretical linguistics and poetics, The Hague; Paris: Mouton.

Vega Montiel, A. (2010) La responsabilidad de la televisión mexicana en la erradicación de la violencia de género contra las mujeres y las niñas. Apuntes de una investigación diagnóstica. Revista Comunicación y Sociedad. Pp. 35-76.

Verón, E. (1987) La Semiosis Social, Barcelona: Gedisa, . (1980): Discurso, poder, poder del discurso. Anais do Primer Coloquio de Semiótica. pp. 1- 8.

UNICEF (2007). La violencia doméstica contra mujeres y niños. Florencia, Italia: UNICEF. 